\title{
Species Diversity and Feeding Guilds of Birds in Paya Indah Wetland Reserve, Peninsular Malaysia
}

\begin{abstract}
The objective of this study was to examine the bird species diversity and feeding guilds in Paya Indah Wetland Reserve, Peninsular, Malaysia. Distance sampling-point count method was used to survey the bird species. A total of 13872 birds belonging to 100 species and 38 families were recorded. The results show that Treron vernans (12.42\%), Pycnonotus goiavier (12.13\%), Geopelia striata (7.58\%), Porphyrio porphyrio (6.87\%) and Streptopelia chinensis $(6.33 \%)$ were the most dominant species in the area. The Ardeidae was the most dominant family with nine species and sixteen families were rarest only with one species each. The highest bird diversity was observed in Marsh swamp (Shannon's N1 $=27.16$ ), while the lowest was in Patchy shrubland (Shannon's N1 = 22.51). The highest bird species richness was observed in Marsh swamp (Margalef's R1 = 9.52), while the lowest was observed in open water bodies (Margalef's R1 =7.35). The evenness of individuals among the species was higher in Marsh swamps (Pielou $\mathbf{J}=0.71$ ) and lower in Patchy shrubland (Pielou $\mathbf{J}=$ 0.67). Analysis of variance and Tukey (HSD) tests showed that bird species among habitats is significantly different $(\mathrm{F} 4,495=8.82 \mathrm{p}<0.0001)$. Feeding guilds indicated that insectivore was the most dominant group (37\%), while Carnivore/Insectivore and Granivore were the least dominant groups (3\% each) in all five habitats. This study clearly indicated that Paya Indah Wetland Reserve is highly important in providing food resources, shelter, nesting and roosting sites for wide range of bird species.
\end{abstract}

Keyword: Wetland birds, diversity, richness, feeding guilds, habitat 